\title{
O MICROCRÉDITO URBANO QUE NASCE DA SOLIDARIEDADE DO MICROCRÉDITO RURAL: O CASO DA SOLCREDI
}

\author{
Luiza Maria da Silva Rodrigues* \\ Francieli Pilati Gervasoni** \\ Norma Kiyota***
}

\begin{abstract}
Resumo
As operações de crédito ao longo da história foram responsáveis pelo estímulo e crescimento das economias no mundo todo. De certa forma, obter crédito significa confiança que alguém ou uma instituição financeira deposita nas intenções do financiado. Contudo, com o encarecimento do dinheiro, as altas taxas e a exigência de garantias que dificultam cada vez mais o acesso, populações mais carentes têm encontrado nas microfinanças a oportunidade de retomar suas relações de confiança e manter ativas suas relações econômicas. No sudoeste do Paraná, os agricultores familiares, já acostumados a operar com microcrédito através das Cooperativas de Crédito Rural com Interação Solidária (Cresol), passaram, a partir de 2012, a possibilitar microfinanças urbanas para trabalhadores que operam como autônomos ou na informalidade e não possuem acesso a créditos subsidiados oficiais em redes bancárias convencionais. Dessa forma, replicaram a experiência da "solidariedade financeira" vivida para acessar o crédito rural nos anos 1990.
\end{abstract}

Palavras-chave: Microfinanças. Serviços Econômicos. Solidariedade. Desenvolvimento.

\footnotetext{
* Mestre em Desenvolvimento Regional pela Universidade Tecnológica Federal do Paraná (UTFPR/Pato Branco), analista de Relações Cooperativas do Instituto de Formação do Cooperativismo Solidário (Infocos). E-mail: rluizamaria@gmail.com.

** Mestre em Desenvolvimento Rural Sustentável, pela Universidade Estadual Oeste do Paraná (Unioeste/ Marechal Cândido Rondon), analista pedagógica do Instituto de Formação do Cooperativismo Solidário (Infocos). E-mail: francieli.pilati@gmail.com.

*** Doutora em Desenvolvimento Rural, docente do Programa de Pós-Graduação Stricto Sensu em Desenvolvimento Regional da Universidade Tecnológica Federal do Paraná (UTFPR/Pato Branco).

Email: kiyota.norma@gmail.com
} 


\section{Introdução}

A necessidade de incluir as pessoas em um processo de desenvolvimento mais dinâmico perpassa por diferentes estratégias, em sua maioria, endógenas. Contudo, no desenvolvimento de ações de microfinanças, parece ser uma iniciativa em que há uma força-tarefa entre governos, Organizações Não Governamentais (ONGs), grupos privados e outras sociedades empenhadas em inserir populações fragilizadas ao sistema financeiro e ao acesso a recursos econômicos.

Essas parcerias objetivam dialogar e, acima de tudo, apresentar possibilidades de reduzir a pobreza e possibilitar, a milhares de empreendedores, o capital financeiro que os estimule a se fortalecer e a desenvolver suas comunidades locais, constituindo-se em um método participativo entre os recursos e instituições que vêm de fora, com a capacidade de superação e trabalho dos que vivem nas áreas atendidas por projetos de microfinanças.

Entre os setores que atuam com as microfinanças, as cooperativas de crédito são as mais conhecidas. Contudo, uma série de outras iniciativas soma-se nesta estratégia em que os valores de repasses são apenas um elemento na busca pela melhoria econômica das pessoas envolvidas, pois há uma extensa rede de organizações que, além do microcrédito, oferecem outros serviços financeiros e ainda de capacitação e aproximação entre os empreendedores e seus mercados potenciais. O cooperativismo, desde a sua criação, sempre foi uma ferramenta importante e gerador de capital humano, porque foca no envolvimento das pessoas e, ainda, estimula economicamente o trabalho e produção.

As Cooperativas de Crédito Rural com Interação Solidária (Cresol), bem como as outras cooperativas que surgiram no sudoeste do Paraná, a partir do debate do cooperativismo solidário, concretizaram importantes ferramentas para debater o desenvolvimento local sustentável 
a partir de processos integrados entre crédito, produção, comercialização e outros ramos, deslocando o debate centrado apenas na agricultura para extrapolar em outros interesses da comunidade local onde este cooperativismo se relaciona.

O cooperativismo de perspectiva solidária do sudoeste do Paraná tem sido pioneiro na atuação de microcrédito e microfinanças, desde a criação das primeiras cooperativas da Cresol, quando operavam com créditos concedidos pelo fundo de crédito rotativo, constituído com recursos de ONGs internacionais que buscavam viabilizar pequenas cadeias produtivas para agricultores familiares desassistidos pelas políticas de crédito oficial nos anos 1980 e 1990.

Além disso, como suas coligadas, possui uma Cooperativa de Tecnologia e Serviços (Cresoltec), uma Administradora e Corretora de Seguros (Cresol Seguros), um Instituto de Formação do Cooperativismo Solidário (Infocos) e uma Associação Nacional de Microempreendedores Solidários Urbanos e Rurais, a Solcredi, objeto deste estudo.

A experiência da Solcredi foi uma iniciativa de laboratório, que serviu de arcabouço para que as cooperativas Cresol passassem a atuar no segmento de microcrédito urbano, visto que, em 2015, uma normativa do órgão de regulamentação do Sistema Financeiro, o Banco Central do Brasil (BACEN) redefiniu públicos e faixas de enquadramento a todas as instituições de crédito cooperativadas, entre estas, a Cresol. Essa normativa gerou a possibilidade de atender os agricultores familiares como público preferencial; contudo, abrindo um leque de possibilidades de atender outras categorias profissionais e o público em geral, segundo a Resolução $n^{\circ} 4.434$ (BACEN, 2015).

A partir da análise qualitativa, vamos apresentar a experiência da Solcredi, como possibilidade válida na ampliação de serviços creditícios a microempreendedores urbanos e individuais, como forma de estimular a solidariedade financeira entre os trabalhadores urbanos e rurais no sudoeste do Paraná. 
Inicialmente, optou-se por realizar uma revisão bibliográfica, apontando um pequeno histórico do tema do microcrédito e das microfinanças no mundo e no Brasil.

\section{Microcrédito e microfinança: conceitos e definições}

$O$ que se observa em literaturas consultadas (ABRAMOVAY,2012; YUNUS, 2013; BARONE et. al, 2002; BÚRIGO, 2010), e se torna consenso para a elaboração deste artigo, é que, para este debate, não há uma referência única para explicitar o que é o microcrédito. Contudo, é a experiência e afirmação de que se trata de algo que nasce historicamente para atender populações excluídas ou desassistidas de programas oficiais de crédito, tanto urbanos quanto rurais. Isso porque são populações que economicamente demonstram sua fragilidade econômica e buscam nos pequenos negócios uma oportunidade de romperem com sua situação de precariedade.

Diversas têm sido as tentativas de padronizar o uso dos conceitos de microcrédito e microfinanças. Textos de pesquisadores estrangeiros, principalmente os de língua inglesa, os tratam (microcredit e microfinance) quase como sinônimos, oferecendo aqui e ali sutis diferenças. Coelho (2006) e outros pesquisadores brasileiros mais recentes sugerem que microfinanças abrange a provisão de serviços financeiros voltados para os pobres, lidando com depósitos e empréstimos de pequena monta, independentemente da possível destinação do crédito tomado. (BACEN, 2008, p. 24).

Para o Serviço Brasileiro de Apoio às Micro e Pequenas Empresas (SEBRAE), citado por Barone et al. (2002, p. 11), o microcrédito tem se tornado sinônimo de "[...] concessão de empréstimos de baixo valor a pequenos empreendedores informais e microempresas do acesso ao sistema financeiro tradicional, principalmente por não terem como oferecer garantias reais”. Já Santana (2012, p. 3), ao discutir estes serviços, afirma que o uso do termo "micro" sugere que: “[...] os recursos que circularão no âmbito das microfinanças são 
inferiores àqueles que giram em torno do sistema financeiro tradicional, baseado na especulação, e cujos efeitos são a concentração e centralização do capital.

Para além do termo, Santana (2012, p. 4) apresenta que:

A diferença entre microfinanças e microcrédito é que o microcrédito é parte das microfinanças, ou seja, a microfinanças abrangem instituições que oferecem serviços financeiros aos carentes como, por exemplo, micropoupança, microseguro, microdoações e, dentre outros, o microcrédito.

É possível compreender que, apesar de comumente ocorrerem sérias confusões com os termos, eles possuem uma correlação, porque objetivam atuar com populações ou segmentos mais enfraquecidos economicamente. O microcrédito faz parte das microfinanças, como mais um serviço além dos demais serviços bancários prestados pela instituição financeira.

Este incipiente debate tende a fortalecer-se frente às iniciativas vividas por comunidades inteiras que se desafiaram a buscar saídas da exclusão econômica em que viviam, mais precisamente, a partir dos anos 1980. O que essas pessoas possuem é a capacidade de superar suas fragilidades e buscar empreender no sentido de inserir-se nos pequenos negócios, como forma de superar sua situação de fragilidade econômica. Uma ação que conta muito mais com a motivação e o empenho pessoal do que o assistencialismo criado por alguma política pública ou caritativa de alguma instituição.

O microcrédito se torna uma válvula propulsora para essas pessoas. Em locais de subdesenvolvimento e em épocas do crescimento do autoemprego, o microcrédito se torna vital diante da impossibilidade de apresentar garantias reais de sobrevivência, em virtude de que muitos empreendedores apenas possuem sua própria mão de obra como recurso de trabalho e, ainda, por vezes, carregam o estigma de que pequenos 
empreendedores e populações excluídas economicamente são más pagadoras de suas obrigações, convicção que tem caído por terra diante das iniciativas mundo afora, como o mais conhecido banco, o Grameen, de Bangladesh.

\section{Breve história do microcrédito: o caso da Grameem Bank}

A história do microcrédito é recente, aproximadamente de 30 anos, com o surgimento da iniciativa, em Bangladesh, de Muhammad Yunus, um economista indiano, que se doutorou nos Estados Unidos e lecionava "teoria econômica" em universidades de seu país.

O Grameen Bank (na língua local, "banco de aldeia"), a instituição criada por Muhammad Yunus para a concessão de crédito a pessoas de baixa renda, tornou-se referência porque os esforços de divulgação de suas ideias e experiências ao redor do mundo deram visibilidade ao microcrédito, a ponto de seu fundador ser agraciado com o Prêmio Nobel da Paz em 2006 (BACEN, 2008).

Yunus decidiu tentar aplicar a teoria das aulas em prática e observou que, em vez de grandes quantias, a população de seu país precisava de poucos valores para libertar-se de serviços de agiotagem e extorsão a que se submetiam para acessar capital de giro para seus pequenos negócios.

Estava a lecionar Economia, na Universidade de Chittagong, nos anos que se seguiram à independência do Bangladesh e havia muitas dificuldades. O país, em vez de progredir, estava a definhar e, em 1974, enfrentávamos um terrível período de fome. Via pessoas a morrer à fome e estava frustrado, sem saber o que fazer para ajudar. Afinal, todas as grandes teorias de desenvolvimento econômico que eu ensinava não contribuíam para nós. (YUNUS, 2003, p. 18).

As ideias de Yunus foram duramente criticadas, desde bancos locais ao Fundo Monetário Internacional (FMI), pois estes assentavam suas opiniões no conservadorismo econômico 
vigente de que os pobres não honrariam suas dívidas, que bancos não têm condições de emprestar sem garantias reais, que a economia não avança com pequenos negócios e que somente grande quantidade de empregos geram dimensões econômicas relevantes ao Estado.

Mesmo tendo sido demonstrado o contrário com a experiência de Bangladesh, esses discursos ainda estão presentes em muitas justificativas de grandes empreendimentos e investimentos públicos nos mais diversos países.

Para provar suas teorias, Yunus deixou o espaço da academia e se dedicou a espalhar sua ideia e proliferar projetos de microcrédito. Em 1983, fundam o Graneen Bank, que se dedica a replicar-se em outros países como iniciativa real de aplicação de microfinanças.

De certa forma, essa iniciativa, como outras que se multiplicaram depois de 1983, rompem com as justificativas apresentadas pela maioria das instituições financeiras que operam no serviço de concessão de pequenos créditos.

Entre os argumentos, os bancos amparam-se nas ideias de que os valores solicitados pelos empreendedores são demasiadamente pequenos, que não remuneram os custos de análise de dossiês, que as disponibilidades de garantias são insuficientes, que podem gerar altas taxas de juros que acabam inviabilizando a operação de pagamento e que, quando oferecem a juros baixos e acessíveis, oferecem baixa rentabilidade à instituição. Ao avaliar o perfil do solicitante, este dificilmente se enquadra no setor do empresariado e possui pouca ou quase nenhuma inserção neste setor profissionalizado.

\section{Microcrédito no Brasil}

Em território brasileiro, o microcrédito surgiu aproximadamente no ano de 1970, com a União Nordestina de Assistência a Pequenas Organizações, que oferecia crédito, 
assistência e capacitação a micro e pequenas empresas

(BARONE et. al, 2002; SANTANA, 2012). Porém, esta instituição,

[...] que financiou milhares de pequenos empreendimentos, mas desapareceu após 18 anos de atuação porque não focalizou um dos principais princípios dessas instituições: o da autosustentabilidade [sic], que deve ser acompanhado com o da profundidade de abrangência, ou seja, deve chegar aos pobres; e o de escala, atingindo um grande número de pessoas. (SANTANA, 2012, p. 3).

Desde então, muitas iniciativas foram criadas para a promoção dessas operações, em sua quase maioria, ações que contaram e contam com apoio de governos, Banco Nacional de Desenvolvimento Econômico e Social (BNDES), Banco do Nordeste, ONGs nacionais e internacionais e sociedades privadas que mantêm fundos para aplicar em focos diversificados.

Encontramos em Barone et al. (2002, p. 15-19) outros inúmeros exemplos que podem ilustrar o quão diverso é o ambiente das microfinanças no Brasil, boa parte destes embasados no desejo de atender e incluir economicamente populações fragilizadas.

Podemos aqui citar a Centro de Apoio aos Pequenos Empreendimentos Ana Terra (CEAPE/RS), que adotou a metodologia de constituir uma rede em 12 estados brasileiros, que atendeu, até dados de 2001, 343 mil operações.

A Crediamigo, mais conhecida experiência, possui uma cobertura no atendimento de microcrédito tanto para o público urbano, quanto para o público rural do Nordeste, atendido principalmente pelo Banco do Nordeste (BNB). A Crediamigo possui dois programas, sendo experiências já com destaque no cenário nacional de microcrédito e microfinanças.

Segundo o anuário 2013, apresentado pela Associação das Organizações de Microcrédito e Microfinanças de Santa 
Catarina (Amcred/SC), as Micro e Pequenas Empresas (MPEs) brasileiras representam um papel fundamental na economia nacional, sendo responsáveis por $20 \%$ do Produto Interno Bruto (PIB) nacional. Isso aponta para o montante de $\mathrm{R} \$ 700$ bilhões, 60\% dos empregos gerados e/ou mantidos, perfazendo 56,4 milhões de postos de trabalhos.

$O$ que regulamenta o microcrédito, quais são suas premissas, quais avanços podem ser destacados e, principalmente, o que determinou a sua regularização? No Brasil, o microcrédito inicia a sua normatização consideravelmente tarde, em meados de 1999. O primeiro documento para a normatização do microcrédito é a Lei n. 9790 , de 23 de março de 1999, que de forma abrangente informa quais requisitos devem ser cumpridos pelas pessoas jurídicas sem fins lucrativos de direito privado, para serem qualificadas como Sociedade Civil de Interesse Público (OSCIP). A Lei institui regras e normas que regem o funcionamento, que ainda pouco se conhece no País pelos microempreendedores.

\section{O surgimento das instituições de microfinanças}

A origem dos serviços financeiros de empréstimos entre grupos para possibilitar acesso a formas de superação da pobreza remonta ao século XVIII, ainda antes da criação das primeiras iniciativas que se tornaram as cooperativas de crédito. De acordo com Búrigo (2010, p. 68),

[...] é preciso entender que o cooperativismo de crédito é resultado de um longo processo de criação de experiências financeiras voltadas aos mais pobres que se iniciou na Europa durante o século XVIII, muito antes de ter sido organizada a primeira cooperativa de crédito.

O ramo do cooperativismo de crédito foi sendo forjado pelos seus idealizadores, como proposta para a superação das 
dificuldades financeiras da classe trabalhadora (BÚRIGO, 2010).

Entre estes pensadores, vários foram os precursores na Europa, em 1848. Schulze Delitze, após tentativas de moinhos comunitários, iniciou a atividade financeira coletivamente para artesões e mestres sapateiros. Friedrich Wilhelm Raiffeisen, por meio da Cooperativa do Pão, baixava o preço da farinha para que mais pessoas pudessem adquiri-la e atuou no recebimento de depósitos dos empresários e na concessão de empréstimos aos pobres. Entretanto, mais tarde percebeu-se que não havia solidariedade no ato, apenas interesse dos empresários em ganhar mais dinheiro dos pobres. Luiz Luzzatti, professor de Economia, organizou vários bancos cooperativos, alguns estendendo à população rural (BÚRIGO, 2010).

Em todas as iniciativas, com maior ou menor grau de influência, as correntes europeias se espalharam pelo mundo:

Em alguma medida as experiências práticas em torno do cooperativismo de crédito coincidiram com a modernização das sociedades em que o dinheiro acabou ganhando cada vez mais espaço em termos culturais e como elo fundamental na consolidação do capitalismo. (BÚRIGO, 2010, p. 78).

O precursor do movimento cooperativista no Brasil foi o padre Theodor Amstad, que por volta de 1901 criou a primeira cooperativa de crédito brasileira na localidade de linha Imperial, município de Nova Petrópolis (RS): a Caixa de Economia e Empréstimos Amstad, posteriormente batizada de Caixa Rural de Nova Petrópolis. De 1902 a 1964, surgiram 66 cooperativas de crédito de tipo Raiffeisen no estado do Rio Grande do Sul (INFOCOS, 2016, p. 18).

Mas, antes mesmo de se tornarem cooperativas de crédito, muitas comunidades e populações experimentavam as ações coletivas de captação e empréstimo. Daí surge a ideia dos microcréditos e de suas instituições, que criam sistemas para 
operar a concessão de empréstimos de pequenos valores a pessoas, empreendedores autônomos ou informais, e outras formas que não acessam estes serviços no sistema financeiro formal.

\section{As Cooperativas de Crédito}

Alguns autores têm afirmado que o microcrédito é fundamental na vida de populações excluídas e invisíveis para as instituições financeiras tradicionais; afinal, possibilita possuir capital de giro e investimentos a partir de uma metodologia específica. Para Junqueira e Abramovay (2005, p. 45), os mais pobres apenas conseguem sobreviver em uma sociedade capitalista porque se apoiam nas finanças informais em suas próprias relações sociais. Para eles, o crédito, nessas populações, é ao mesmo tempo: "Uma forma de dominação social, mas também é um ativo, um meio do qual dispõe a família na obtenção do que necessita para reproduzir-se. São relações estáveis, previsíveis e que se inserem dentro do horizonte social relativamente conhecido dos atores" (JUNQUEIRA; ABRAMOVAY, 2005, p. 45).

Essa força que emana das relações informais também se manifesta nas relações financeiras nas quais os atores estão envolvidos. Embora as operações creditícias, se realizadas em ambiente bancário, pudessem gerar lucratividade, a falta de garantias reais dessa população mantêm o risco alto e causa o desinteresse de instituições bancárias que trabalham com altas taxas de assertividade e de resultados, além da baixa adesão à burocracia exigida pelos sistemas bancários.

Estudos realizados por Junqueira e Abramovay (2005, p. 5) demonstram o quão é ampla a vida financeira das famílias pobres, que estas se desenvolvem à margem do sistema bancário, porque se pautam pelas relações de proximidade. Contudo, uma estratégia de inserção dessas famílias ao Sistema Financeiro Nacional fortalece-se pela constituição de cooperativas. Junqueira e Abramovay (2005, p. 23) afirmam que: 
O custo e a dificuldade em diminuir a assimetria de informação nas atividades de crédito por meio dos métodos bancários tradicionais podem ser equacionados pela qualidade das ligações sociais entre os emprestadores e os credores nas finanças de proximidade: a densidade das relações interpessoais permite o acesso a informações inacessíveis em um quadro de relações estritamente profissionais e com dados puramente cadastrais.

É nesse ambiente que as cooperativas de crédito podem ser mais eficientes em atender essas populações porque atuam em uma correlação entre a relação bancária e as relações por proximidade, situação esta que se assemelha para cenários urbanos e rurais.

\section{O Sistema Cresol}

A proposta inicial baseou-se na história vivida por estas organizações a partir de convênios de cooperação internacional inicialmente realizado entre a Associação de Estudos, Orientação e Assistência Rural (Assesoar) e a ONG Alemã Misereor (INFOCOS, 2010). Este convênio criou um fundo, denominado de Fundo de Crédito Rotativo (FCR), que era gerido por todas as organizações de diálogo da Assesoar e da agricultura familiar da região sudoeste e centro-oeste do Paraná, como os Sindicatos dos Trabalhadores Rurais (STRs), a Comissão Pastoral da Terra (CPT), a Conferência Nacional dos Bispos do Brasil (CNBB) e o Movimento Sem-Terra (MST).

Assim, com o empenho das lideranças e suporte de suas organizações, foi possível, em 1995, a criação das cinco primeiras unidades, localizadas nos municípios de: Dois Vizinhos, Marmeleiro, Capanema, Laranjeiras do Sul e Pinhão. Atualmente, o modelo adotado pelo Sistema Cresol atua em nove estados brasileiros: Paraná, Santa Catarina, Rio Grande do Sul, Minas Gerais, Espírito Santo, Rondônia, Rio de Janeiro, Goiás e São Paulo, com cerca de 192 mil famílias cooperadas, além de aproximadamente mil conselheiros e 1,3 mil colaboradores (INFOCOS, 2016). 
Aliado a isso, estão também as suas coligadas: Infocos, Cresoltec, Cresol Seguros e a Associação Nacional de Microempreendedores Solidários Urbanos e Rurais (Solcredi), uma Organização da Sociedade Civil de Interesse Público (OSCIP), cujo objetivo é atender especialmente pequenos empreendimentos urbanos, ou filhos de agricultores familiares, que se localizam no meio urbano e que possuem empreendimentos com necessidades creditícias.

\section{Metodologia}

Este artigo privilegiou o método de estudo de caso e entrevista, com análise qualitativa e por considerar as reflexões a partir das práticas sociais empíricas. O método científico do estudo de caso pode parecer possuir imprecisão e falta de objetividade frente a outros métodos, mas permite uma dialogicidade entre a vivência do autor com a sua observação da realidade estudada.

A observação empírica de estudo de caso pode possuir suas limitações, que se constituem na impossibilidade de generalização, mas oferece a oportunidade de se constituir em um objeto em que muitas possibilidades de interpretação são oferecidas ao autor, e este, em sua fase exploratória, pode construí-la com o embasamento teórico oferecido.

No caso do estudo proposto, trata-se de uma observação empírica a partir das práticas de solidariedade já desenvolvidas pelo Sistema Cresol ao longo de 20 anos de história.

Para construção desta reflexão, foi necessário consultar o referencial teórico disponível sobre as microfinanças e microcrédito - tema central da criação da Solcredi -, e a realização de entrevistas com os gestores da instituição. A partir das reflexões oferecidas pela leitura deste referencial, foi possível dialogar sobre a experiência da Cresol e sua experimentação no microcrédito urbano, área de inserção da prática observada. 


\section{Resultados}

O termo microfinanças refere-se à prestação de serviços financeiros adequados e sustentáveis para a população de baixa renda, tradicionalmente excluída do sistema financeiro tradicional, com utilização de produtos, processos e gestão diferenciados.

Nessa linha, entidades de Micro Finanças (IMFs) são entendidas como aquelas pertencentes ao mercado microfinanceiro, especializadas em prestar esses serviços, constituídas na forma de ONGs, OSCIPs, cooperativas de crédito, Sociedades de Crédito ao Microempreendedor e à Empresa de Pequeno Porte (SCMs), fundos públicos, além de bancos comerciais (BACEN, 2008, p. 23).

Uma das primeiras iniciativas das microfinanças experimentada pelos agricultores familiares do sudoeste do Paraná foi a criação das pequenas cooperativas de crédito do sistema Cresol, que atua na missão de aproximar e facilitar o acesso a serviços financeiros com inclusão social, destinado aos agricultores familiares.

Com base na Lei no 9.790, de 23 de março de 1999, foi criada a Solcredi, uma organização para atender microempreendedores coligada do Sistema Cresol, a qual traz o seguinte regulamento: "Dispõe sobre a qualificação de pessoas jurídicas de direito privado, sem fins lucrativos, como Organizações da Sociedade Civil de Interesse Público, institui e disciplina o Termo de Parceria, e dá outras providências" (BRASIL, 1999).

Constituída em 2012, a Associação Solcredi surge para oferecer os serviços creditícios a trabalhadores e empreendedores urbanos, que, pela sua lógica de informalidade, não estavam inseridos no sistema financeiro tradicional ou o utilizavam muito restritamente. Constituída com metodologia de captação e gestão própria, tornou a iniciativa uma possibilidade de experimentação, sem comprometer as 
carteiras creditícias das cooperativas Cresol, ao mesmo tempo em que a análise de sua saúde financeira pudesse ser avaliada de forma independente.

Essa sem dúvida é uma das principais vantagens para o Sistema, pois pode oferecer um novo serviço para um público diferente sem trazer risco para as cooperativas. Além do mais, pode ser uma porta de entrada de um tipo novo de cliente que foi experimentado e aprovado conforme seu histórico dentro da SOLCREDI. (INFOCOS, 2015, p. 76).

Entre suas primeiras definições (INFOCOS, 2015, p. 73), evidencia-se localizar cooperativas que já possuíam essa proximidade e diálogo com a comunidade local.

Dessa forma, a Associação Solcredi instalou-se nos municípios de Francisco Beltrão, Marmeleiro, Pranchita e Santo Antônio do Sudoeste, todas no Paraná. De acordo com informações disponibilizadas no site da Solcredi ([s.d.]), entre os principais produtos creditícios oferecidos, atua com clientes individuais, associações comunitárias, cooperativas de produção e comercialização, empresas individuais, prestadores de serviços autônomos ou informais (comércio em geral, profissionais liberais, doceiras, costureiras, restaurantes, confeiteiras, autônomos, ambulantes, clínicas de estéticas, vendedores, oficinas mecânicas, salões de beleza, entre outros) e microempreendedores. Não é observado o critério da formalidade para cessão do crédito, e sim, um projeto de negócio, proposto pelo cliente.

Como prestadora de serviços, a Solcredi, por meio de seus Agentes de Crédito, visita bairros, comunidades e comerciantes para apresentar a instituição, reconhecer necessidades e, em casos necessários e possíveis, oferecer o crédito.

A metodologia de abordagem, segundo entrevistados na pesquisa, aproxima-se muito de uma metodologia adotada por outras instituições de microcrédito e OSCIPs: balanço 
falado. Este método possibilita ao agente identificar e mapear sistemas de renda primários em que o futuro cliente nem sempre identifica como renda, mas que, do ponto de vista financeiro, fica oculto, uma vez que estes clientes não possuem uma movimentação monitorada por sistemas contábeis.

É a informalidade econômica que mantém esses indivíduos movimentando em torno da atividade produtiva, e esse mapeamento realizado pelo Agente de Crédito aproxima o agente da realidade vivida e ajuda a identificar futuras necessidades de aplicação de sua carteira.

Contudo, na Solcredi, após a visita do Agente de Crédito, segundo as entrevistas coletadas, identificou-se que a proposta de crédito, em caso de efetivação pelo cliente, recebe uma avaliação de um conjunto de pessoas, denominada de Comitê.

Entre os principais produtos financiáveis, atualmente, a Solcredi oferece:

Aquisição de ferramentas, máquinas e equipamentos novos e usados; Recuperação e/ou conserto de máquinas, veículos utilitários e equipamentos, efetuados por empresa tecnicamente idônea e que dê garantia de funcionamento; Melhoria e/ou ampliação de instalações, desde que destinados a negócio. Capital de giro para aquisição de Mercadorias; Matériaprima; Insumos. (SOLCREDI, [s. d.], [s. p.]).

A criação da Associação de Micro e Pequenos Empreendedores Rurais e Urbanos tem o objetivo de proporcionar o acesso a recursos financeiros para a população que trabalha por conta própria, mas que tem dificuldades de conseguir empréstimos em instituições financeiras em virtude de, na sua maioria, se manterem na informalidade, ou não possuírem garantias, por se tratar de trabalhadores autônomos que não possuem declaração de renda, como forma de justificar sua movimentação financeira.

Segundo os entrevistados, a Solcredi se constituiu em um "laboratório" para reconhecer esse público como 
economicamente ativo, compreender e aperfeiçoar as metodologias de abordagem, assim como os instrumentos técnicos e tecnológicos necessários para a gestão de uma carteira de microcrédito, sendo decisiva para que, em 2016, a Cresol pudesse estruturar melhor seus produtos e serviços a um público amplo.

A Resolução no 4.434, de 2015, que reorganiza e classifica as cooperativas de crédito no Brasil, praticamente transformou todas as cooperativas de crédito segmentadas em múltiplas, tornando a "exclusividade" de atuação com agricultores familiares, em "público preferencial", mas oportunizando a inúmeras outras categorias de associar-se, em caso de interesse (BACEN, 2015).

Segundo os entrevistados, "[...] esta vivência oferecida pela Solcredi, recoloca a Cresol, internamente, a um novo desafio, de enxergar no meio urbano a outra face do desenvolvimento local, permeado por pessoas que carecem de apoio creditício e serviços financeiros”.

Desde a criação da Solcredi, em 25 de abril de 2012, foi possível identificar que a grande maioria de seus clientes se constitui nos prestadores de serviço, conforme apontado no Quadro 1:

Quadro 1 - Ramos de origem dos microempreendedores

\begin{tabular}{|c|c|c|}
\hline Divisão & \% dos empréstimos & \% do valor \\
\hline Produção & $3,33 \%$ & $3,17 \%$ \\
\hline Comércio & $21,67 \%$ & $20,23 \%$ \\
\hline Serviço & $48,33 \%$ & $47,67 \%$ \\
\hline Misto & $26,67 \%$ & $28,94 \%$ \\
\hline
\end{tabular}

Fonte: elaboração dos autores (2016), a partir de dados extraídos de relatórios internos.

Observamos, no quadro anterior, que uma grande fatia dos recursos é destinada a trabalhadores que prestam serviços, tais como proprietários de salões de beleza, de panificadoras, 
pedreiros, manicures, eletricistas, azulejistas e demais profissionais cuja remuneração resulta de seu próprio trabalho.

Quando apontado que 21,67\% atuam com a área de comércio, significa que são profissionais que possuem a relação de comercialização de bens junto com serviços, como vendedores ambulantes de vestuário, cosméticos, infraestrutura, eletrônicos e outros bens de consumo.

A área mista é identificada por profissionais que atuam na prestação de serviço, aliados à comercialização, como um eletricista que também comercializa materiais elétricos, donos de salões de beleza que atuam junto coma área de comércio de roupas ou produtos cosméticos.

Para uma melhor compreensão do que se tratam estas áreas, é necessário identificar o que diz o Portal do Empreendedor, uma ferramenta criada pelo governo federal que ajuda a identificar, diante das atribuições desenvolvidas pelo autônomo ou empreendedor individual, qual o setor prioritário da sua atividade.

No quadro a seguir, apresentamos os valores médios de contrato, que demonstram uma necessidade de valores entre $R \$ 10$ mil e $R \$ 15$ mil. Observa-se que a maioria destes provém de profissionais autônomos ou informais, que não dispõe de garantias reais para acessar créditos em instituições tradicionais.

\section{Quadro 2 - Valores médios dos contratos}

\begin{tabular}{|l|c|}
\hline Faixa de valores & \% de contratos \\
\hline Até $R \$ 2$ mil & $3,33 \%$ \\
\hline De $R \$ 2$ mil a $R \$ 3$ mil & $28,33 \%$ \\
\hline De $R \$ 3$ mil a $R \$ 5$ mil & $8,33 \%$ \\
\hline De $R \$ 5$ mil a $R \$ 10$ mil & $11,67 \%$ \\
\hline De $R \$ 10$ mil a $R \$ 15$ mil & $48,33 \%$ \\
\hline
\end{tabular}

Fonte: elaboração dos autores (2016), a partir de dados extraídos de relatórios internos. 
De acordo com os entrevistados, entre as 320 operações realizadas, o valor médio dos contratos é de $\mathrm{R} \$ 7.000,00$, mas foi possível criar, a partir de dados de relatórios consultados pelos autores, que, se forem somados os valores até $\mathrm{R} \$ 5.000,00$, se atinge $39 \%$ dos clientes, um número considerável de atendimentos. Estes dados indicam que são os pequenos valores que contribuem para saldar as necessidades mais imediatas de seus clientes, como contratos mais curtos.

Ainda é possível perceber que há uma fatia considerável dos clientes da Solcredi que necessita de valores um pouco mais elevados, ou seja, acima de $\mathrm{R} \$ 10 \mathrm{mil}$, totalizando aproximadamente $50 \%$ dos créditos efetivados, que, de acordo com entrevistas coletadas, são necessários em contratos que tratam de propostas de investimentos, ou mistos, como poderemos observar no Quadro 3.

Quanto à utilização do capital, temos a seguinte composição, utilizando-se também na comparação o valor tomado pelos microempreendedores:

Quadro 3 - Principais itens utilizados para contratação

\begin{tabular}{|l|c|c|}
\hline Utilização & \% de empréstimos & $\begin{array}{c}\text { \% do valor } \\
\text { emprestado }\end{array}$ \\
\hline Capital de giro & $55,00 \%$ & $37,50 \%$ \\
\hline Fixo em bens e imóveis & $11,67 \%$ & $17,06 \%$ \\
\hline Misto (fixo e giro) & $33,33 \%$ & $45,38 \%$ \\
\hline
\end{tabular}

Fonte: elaboração dos autores (2016), a partir de dados extraídos de relatórios internos.

Denota-se que a finalidade de capital de giro, como a aquisição de máquinas, equipamentos e/ou outros bens, é uma necessidade dos microempreendedores, visto que $55 \%$ dos empréstimos foram destinados para esta condição; contudo, há uma relação de que a maior parte dos valores foi para contratos em que há uma soma entre o capital de giro e investimentos.

Apesar do índice de empréstimos ter sido menor na destinação de utilização mista em comparação ao capital de 
giro, o valor emprestado é significativamente superior, o que considera as duas variáveis nessa diferença.

Em linhas gerais, a estruturação dos microempreendedores com relação a imobilizado não é uma característica predominante; porém, nos casos em que o capital foi destinado tanto para a aquisição de imobilizado quanto para capital de giro, a imobilização se deu em alguns casos na renovação de imobilizados.

A segmentação dos recursos emprestados é significativa na área de prestação serviços, tanto no total de recursos emprestados quanto nos valores repassados, conforme observado pelos autores.

Não foi possível durante a pesquisa sistematizar ou obter informações sobre outras variáveis consideráveis, como o percentual de informalidade na relação ao microempreendedor formalizado, porque a instituição não adota este critério nas avaliações de seus comitês.

\section{Considerações finais}

Em tempos de questionamentos aos projetos hegemônicos de desenvolvimento, há um apelo ao estímulo das diversidades, inclusive produtivas, na busca de elementos que contribuam com o crescimento dos territórios. Becattini (1994, p. 3) afirma que a convergência geográfica, somada aos laços culturais - características históricas e naturais - podem ser a base para um processo virtuoso de desenvolvimento, pois as pessoas tendem a buscar redes solidárias para suas relações comerciais.

$\mathrm{E}$, dessa forma, inúmeros pequenos empreendimentos constroem seus planejamentos para o crescimento do negócio, a partir da sua rede próxima de relacionamentos, com vizinhos, conhecidos e amigos que podem fazer uso dos serviços que prestam.

O microcrédito se torna não somente o dinheiro em si, mas a oportunidade de modificar atitudes e de ampliar a rede 
de relacionamentos pessoais e comerciais do empreendedor. Esta mudança proporcionada aos indivíduos empreendedores contribui para a autoestima dos envolvidos, a tomada de atitudes responsáveis, diante do compromisso junto aos seus clientes, com a instituição financeira e construção do desenvolvimento da cultura de valorização do crédito, e de sua manutenção.

Nos casos específicos de operações com grupos excluídos, subsumidos ou desempoderados, os efeitos alémeconômicos são maiores ainda do que em grupos apenas de empreendedores comerciais, pois os programas destinados a estes grupos vêm somados a inúmeras oportunidades de acesso à informação, cursos profissionalizantes e busca por mercados alternativos que não são objetos de disputas com grandes mercados de produtos-homogeneização. Estas economias que mantêm aquecidas muitas comunidades se tornam a expressão e identidade do grupo.

O desenvolvimento, nessa perspectiva, passa a se enraizar e a modificar quadros de dependência e exploração de grupos ou comunidades. Torna-se uma possibilidade de mudar sua realidade por dentro dela mesma; afinal, além do capital financeiro, esse mecanismo do crédito gera nova cultura, novos sentimentos entre as pessoas, o que aumenta o capital humano que se envolveu nestas novas relações.

De maneira geral, a necessidade apresentada nos setores em que os microempreendedores ou autônomos vivem na informalidade é considerável por se tratar de economia não reconhecida pelo sistema financeiro tradicional, isso pode ser constatado no referencial teórico consultado, e que estes se encontram desestimulados a acessar em instituições que exigem a formalidade e garantias reais.

Destarte, temos experiências de norte a sul do País. E, apesar dos créditos serem destinados a microempreendedores e de valores limitados, a movimentação efetuada nesse ramo é consideravelmente relevante, pois se situam em regiões, 
negócios ou situações em que as pequenas economias mantêm

a relação comercial, aliada às relações de confiança entre o empreendedor e o usuário de seus serviços.

Conforme afirmado por Yunus, ironicamente, o microcrédito que é construído em redor, pelo e com o dinheiro, não tem no seu âmago, na sua raiz profunda, nada a ver com o dinheiro. Tem a ver com ajudar as pessoas a realizarem totalmente os seus potenciais. Não tem a ver com capital financeiro, mas com capital humano. $\mathrm{O}$ dinheiro é uma mera ferramenta que ajuda a realizar sonhos, que auxilia as pessoas mais pobres e mais desafortunadas a ganharem dignidade, respeito e um sentido para as suas vidas (YUNUS, 2003).

O microcrédito, de forma geral, tem sido inovador na sistemática de concessão de crédito, pois desmitifica que a única forma de garantia é a que paga a conta; a propósito, as garantias apresentadas no microcrédito, em sua maioria avalistas, o que auxilia na baixa inadimplência, é o acompanhamento, uma característica metodológica do microcrédito.

O microcrédito é uma forma de apoiar iniciativas de autoemprego por parte de trabalhadores com iniciativa e ideias que, em sua maioria, apresentam resultados satisfatórios ao longo do tempo.

A Solcredi permitiu verificar a necessidade de microcrédito para micro e pequenos empreendedores, em alguns municípios; todavia, analisando sob o aspecto quantidade de lugares onde a Cresol atua, pode ser encarada como uma demanda crescente. A experimentação ou o laboratório que se tornou a Solcredi desde 2012, como citado pelos entrevistados, propõe-se a ser uma forma de trazer à luz, pessoas, empreendedores que na informalidade mantêm-se vivos e ativos por meio de seu trabalho, garantindo renda a eles e a suas famílias.

Essa iniciativa, que inicialmente pode parecer apenas um negócio, se aprofundada, pode exprimir o que de mais solidário se pôde materializar na cooperação econômica; 
afinal, por meio do microcrédito, os agricultores familiares e os trabalhadores urbanos compartilham e crescem juntos e geram desenvolvimento local.

\section{Referências}

ABRAMOVAY, Ricardo. Cinco anos de Crediamigo. São Paulo: USP, 2012.

ANDC - Associação Nacional de Direito ao Crédito. O microcrédito na Europa. 2010. Disponível em: <http://www. microcredito.com.pt/microcredito-no-mundo/microcredito-naeuropa/o-microcredito-na-europa/30 > . Acesso em: 20 jul. 2014.

BANCO CENTRAL DO BRASIL. Microfinanças: o papel do Banco Central do Brasil e a importância do cooperativismo de crédito. Brasília: BCB, 2008.

. Resolução no 4.434 de dezembro de 2015. Brasília: BCB, 2015. Disponível em: <http://www.bcb.gov.br/pre/normativos/ busca/normativo.asp?tipo=Res\&ano=2015\&em umero $=4434>$. Acesso em: 15 maio 2016.

BANCO DO NORDESTE. Relatório 2013. Programa de Microfinanças do Banco do Nordeste. 2013.

BARONE, Francisco Marcelo; LIMA, Paulo Fernando; DANTAS, Valdi; REZENDE, Valéria. Introdução ao microcrédito. Brasília: Conselho de Comunidade Solidária, 2002.

BECATTINI, Giácomo. O Distrito Marshalliano: Uma noção sócio-econômica. In: BENKO, Georges; LIPIETZ, Alain (Org.). As regiões ganhadoras. Distritos e Redes: Os novos paradigmas da Geografia Econômica. Oeiras-Portugal: Celta Editora, 1994. p. 45-58.

BRASIL. Lei no 9.790, de 23 de março de 1999. Dispõe sobre a qualificação de pessoas jurídicas de direito privado, sem fins lucrativos, como Organizações da Sociedade Civil de Interesse Público, institui e disciplina o Termo de Parceria, e dá outras providências. Diário Oficial da República Federativa do Brasil, Brasília, DF, 24 mar. 1999. Disponível em: <http://www.planalto.gov.br/ccivil_03/leis/ L9790.htm>. Acesso em: 20 jul. 2014. 
BÚRIGO, Fábio Luiz. Finanças e solidariedade: cooperativismo de crédito rural solidário no Brasil. Chapecó: Argos, 2010.

INSTITUTO DE FORMAÇÃO DO COOPERATIVISMO SOLIDÁRIO. Cooperativa Escola: Bem - Vindo à Cresol. Francisco Beltrão: Grafisul, 2016.

. Curso de Formação para Conselheiros de Administração da Central CRESOL Baser. Francisco Beltrão: Grafisul, 2015. (Série Cooperativa Escola Gestão e Administração, Ano I).

. Ensaios sobre o Cooperativismo Solidário. Londrina: Midiograf, 2010.

- Origem da cooperação. História e concepção do cooperativismo. Francisco Beltrão: Grafit, 2006. Cadernos I. (Série Gestão do Cooperativismo).

RELATÓRIO ANUAL DA AMCRED-SC. A força do microcrédito catarinense. Florianópolis, set. 2012.

2013.

A força do microcrédito catarinense. Florianópolis, set.

JUNQUEIRA, Rodrigo Gravina Prates; ABRAMOVAY, Ricardo. A sustentabilidade das microfinanças solidárias. Revista ADM, São Paulo, v. 40, n. 1, p. 19-33, mar. 2005.

ROSALES, Ramon. Marco jurídico para as instituições de microcrédito. Maio, 2000. (Seminário Internacional BNDES Microfinanças).

SANTANA, Clarissa Almeida de. Uma leitura das finanças solidárias como alternativa de acesso ao crédito para a população de baixa renda. In: ENCONTRO DA ANPAD, 36., 22-26 set. 2012, Rio de Janeiro. Anais... Rio de Janeiro: ANPAD, 2012. p. 1-16.

SOLCREDI. Portal da Associação Nacional de Microempreendedores Urbanos e Rurais. [s.d.]. Disponível em: <www.solcredi.com.br>. Acesso em: 10 jun. 2016.

YUNUS, Muhammad. O banqueiro dos pobres. São Paulo: Ática, 2003.

Submetido em: 20/07/2017

Aceito em: 30/07/2017 
188 Revista Grifos

\title{
THE URBAN MICROCREDITTHAT IS BORN FROM THE SOLIDARITY OF RURAL MICROCREDIT:THE CASE OF SOLCREDI
}

\begin{abstract}
Credit operations throughout history have been responsible for stimulating and growing economies around the world. In a way, getting credit means trust that someone or a financial institution deposits in the intentions of the financier. However, with the increase in money, high rates and the demand for guarantees that make it increasingly difficult to access, the poorest populations have found in microfinance the opportunity to resume their relationships of trust and maintain their economic relations. In the southwestern region of Paraná, family farmers, already accustomed to operate with microcredit through the Cooperatives of Rural Credit with Solidarity Interaction (Cresol), started, at 2012, to enable urban microfinance for workers who operate as self-employed or informal work and not have access to official subsidized credits in conventional banking networks. In this way, they replicated the experience of "financial solidarity" lived to access rural credit in the 1990s.
\end{abstract}

Keywords: Microfinance. Economic Services. Solidarity. Development. 